\title{
The Development of Technology for Higher Education Institution's Administrative Personnel Assessment
}

\author{
Olga Yurevna Bakhtina ${ }^{1}$, Andrey Vladimirovich Kirillov ${ }^{1}$, Sergey Askoldovich Matyash ${ }^{1} \&$ \\ Olga Aleksandrovna Urzha ${ }^{1}$ \\ ${ }^{1}$ Russian State Social University, Moscow, Russia \\ Correspondence: Olga Yurevna Bakhtina, Russian State Social University, Ul. Wilhelm Pieck, the house 4, \\ building 1, 129226 Moscow, Russia.
}

Received: November 15, $2014 \quad$ Accepted: January 5, 2015 Online Published: April 28, 2015
$\begin{aligned} & \text { doi:10.5539/ies.v8n5p179 } \\ & \text { URL: http://dx.doi.org/10.5539/ies.v8n5p179 }\end{aligned}$

\begin{abstract}
The main approaches for development of assessment technology of higher education institution's administrative personnel are considered in this article. Alongside with it the following is defined: purposes, formation principles, indicators and criteria of the assessment system, rating scale, the procedure and order of assessment process of higher education institution's administrative personnel personal performance. Criteria of an assessment of personal efficiency of employees of higher education institution are considered in case the employee significantly exceeds expectations ("image" of a perfect employee), exceeds expectations, meets expectations, needs an improvement and doesn't meet expectations ("image" of the bad employee). The procedure of payments of the individual size of an award of the worker proceeding from the received assessment is shown.
\end{abstract}

Keywords: procedure of personnel assessment, system of higher education institution's assessment, balanced system of indicators, jobs grading, assessment technology of higher education institution's administrative personnel personal performance

\section{Introduction}

You must admit, that it is rather frequent for a well-known Reshetnikov's picture "Opyat' dvoika" (F-mark again) to come back to your memory when expecting the results or even the draft of an assessment procedure. Quite an unpleasant association, but even without it very few people anticipate and feel pleasure while preparing for estimating procedures, checks or reports-even if you are sure that there is nothing to fear.

On the other hand, without an assessment of personnel performance it is impossible to define a fair material remuneration (Fionova, 2014, p. 73). As for the Russian higher education institutions, as a rule, mainly the academic staff (AS) is assessed regularly. And it is obvious because it forms the core of a higher education institution, besides that, indicators and criteria of this assessment - no matter how you treat them-are generally developed by the Ministry of Education and Science of the Russian Federation (MESRF) within annual monitoring of efficiency of higher education institutions. The great interest is represented by researches Kibanova (2013) in this area, and also the innovative methods of an assessment of quality of professional activity of pedagogical shots of the higher school developed under the leadership of Urzha (Urzha et al., 2009, pp. 78-125).

However, it is not unusual when administrative and educational support personnel of higher education institutions are evaluated by their direct chiefs only subjectively. As a result, the material motivation of this category of educational institutions employees does not always depend on their efficiency. At times the principles of personal devotion, loyalty to the management, and even family ties go first. And after all the reputation of university in the conditions of the global competition of the higher school in many respects depends on objective trust to this group of workers (Alekseev et al., 2013).

\section{Method}

When new management of Russian State Social University (RSSU) faced a necessity to improve significantly an efficiency of the university, it was started with ranging, optimization and development of the administrative personnel assessment system. The task group studied thoroughly an experience of domestic and foreign higher education institutions, businesses (Voltchkova \& Rasskazov, 2009) and public institutions in this sphere. It is 
necessary to distinguish method of expert evaluations and its versions from the applied expert and intuitive methods of forecasting of control systems-the Delfi method and a method of SWOT analysis; method of brain storm and method synectics (Ageev, 2010, p. 15).

As a basis for the assessment technology "Five+" system of Sberbank of Russia was used. This system was developed by one of the article's authors. Results of sociological researches of personnel capacity of the higher school were considered depending on various type of motivation and ways of stimulation of workers, scientific and methodical providing an assessment of their activity, development on estimates of efficiency of staff of average educational institutions of Russia, in particular school No. 1497. Besides that, methodical recommendations for defining of efficiency indicators and professional service productivity of the Federation Council of the Russian Federation's government employees were used (Baklanov, 2006) and its evaluation tools (Baklanov, 2012).

However, the task group considered inappropriate to adopt someone's ready technique. Certainly, when developing the system of personnel assessment it is necessary to use all positive aspects provided by accumulated experience and to learn the lessons from it. But it is necessary to be critical towards that experience in relations to conditions of the particular organization. Under no circumstances it is possible to apply an experience formally-it is like placing a tracing-paper on existing realities and personal needs.

Improvement of motivation system became one of the main objectives for a new assessment system for administrative personnel of a higher education institution (Kibanov, 2014, pp. 397-401). Considering that, material remuneration of employees must be defined according to a labor input of each member to a joint activity, it was decided in the beginning of the process to carry out the grading of posts. Grading is a positioning of posts, i.e. the distribution of posts in organization hierarchy structure according to the value of this post for the organization (Bondaletov, 2007).

While grading the posts, the attention was emphasized on defining of officials functional duties to the benefit of personnel assessment system. Thus it was required to formulate distinctly Key Performace Indicators (KPI) of these duties performing. That gave the chance to use the balanced system of indicators (Balanced ScoreCard, $\mathrm{BSC}$ ) in the assessment and remuneration system of the personnel.

As a basis of defining KPI for executive officials MESRF metrics were used. These metrics, as shown in Figure 1 , were amplified with more detailed indices such as: QS indices, brand awareness, satisfaction indices, quality of processes, market share, free cash flow. It made possible to create a system of responsibility for indicators and effectiveness of RSSU, to increase manageability rate of MESRF monitoring results, to manage RSSU development. Herewith the workload connected with the reporting did not increase.

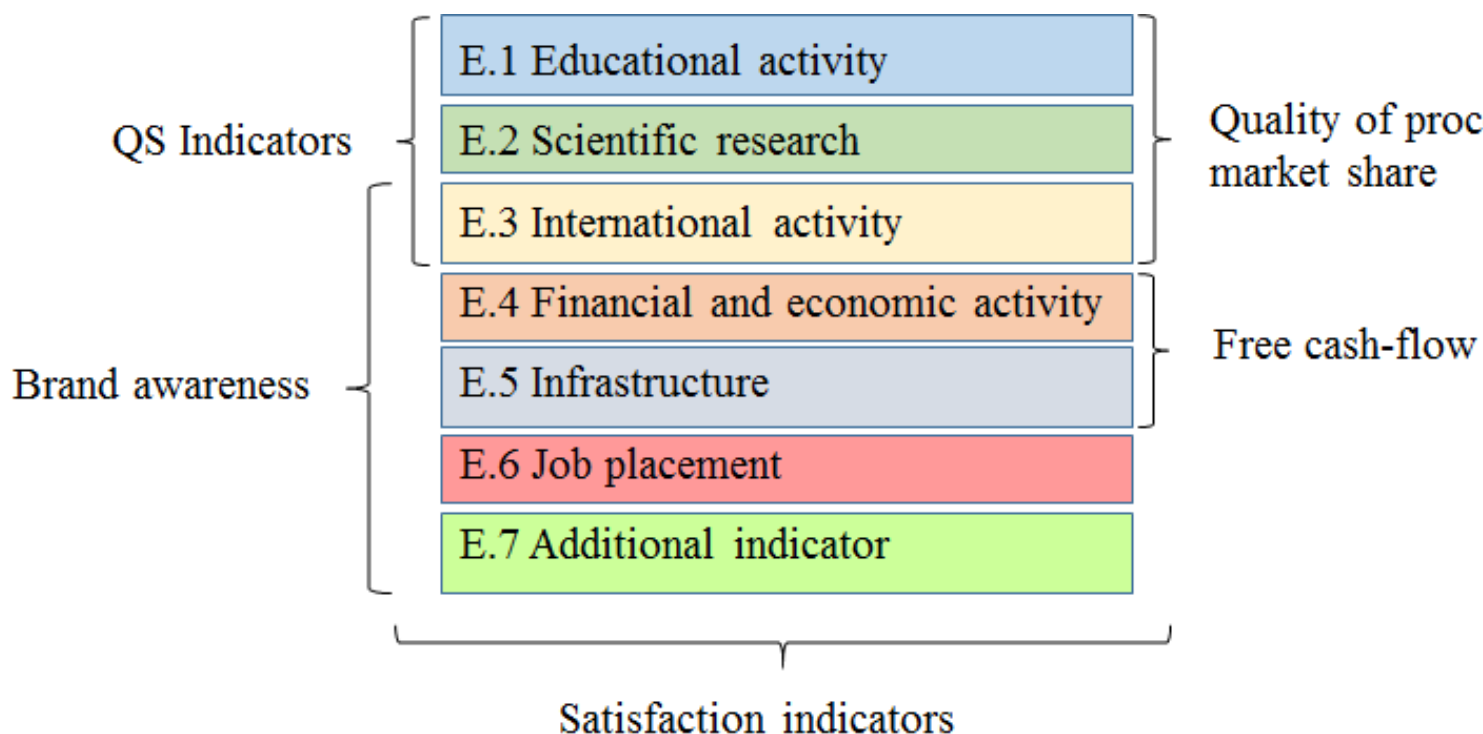

Figure 1. Performance indicators RSSU 
Defining functional duties of executive officials, the most important objectives of RSSU effectiveness increase were taken into account. Job descriptions must be connected with employees' plans for an accounting period directly (Kirillov, 2014, p. 104). Only careful planning able to answer questions like: what to do, when to do, who and by using what will do it-will make it possible to perform functional responsibilities with quality.

As a result, the head of Information Systems and Technologies Management received a functional duty to implement and maintain the system of automated processing for the results of intermediate control, final state assessment and processing of diplomas for graduates. The purposes were: to decrease the enquires of graduates to employment services by acceleration of diplomas processing, that can also give a chance to find a job quicker (MESRF indices) during the period, when the quantity of vacancies is maximum; university image making (brand awareness, a satisfaction index), due to a decrease in number of complaints from graduates concerning late issues of diplomas; improvement of quality of educational processes. The control points for implementation are: test operation, system testing, reaching the full capacity. The indices of assessment are: the period of the order issue from the date of official note providing and the period of diplomas execution from the date of order issue to send down graduates due to successful graduation. (Kaurova et al., 2014)

The purposes to develop the system allowing assessing employees personal efficiency were made according to two different approaches: the University position, an employee position. The new assessment system should give a chance to pay the employees according to the results, but not for any activity, it should encourage: self-improvement, commitment to students, innovations, teamwork, creations of a personnel reserve and rotation of posts, purposeful programs of development of the personnel to optimize process of resources distribution, to create conditions supporting the initiatives of employees, to involve them in positive competition. It involves for the employees: competitive remuneration, transparent and fair payments, opportunity to affect earnings, understanding of objectives, indicators and criteria for successful performance, a guarantee for achievements to be noticed, opportunity for professional and career growth (Chulanova, 2014, pp. 24-67.). Besides that, the work-group had aimed to create universal system of assessment suitable for all employees of the University.

\section{Results}

The technology of assessment was defined in the "Regulation on assessment system of RSSU personnel personal efficiency" based on law acts of the Russian Federation, RSSU Charter, the Labour Contract, Rules of internal labor and educational regulations of RSSU, the Corporate Code of RSSU, orders and instructions of the president of RSSU, the Strategy of RSSU development till 2020, and other local acts of RSSU. The regulation sets: purposes, principles of formation, indices and criteria of an assessment system, assessment scale, the procedure and order of assessment system of RSSU personnel personal efficiency.

\subsection{Purposes and Principles of Assessment}

As a purpose of assessment for RSSU personnel personal efficiency further points were defined: an increase of mutual understanding between employees and management, providing of fair remuneration and objectivity of employees performance assessment, an increase in efficiency of RSSU employee performance, creating standards of behavior and performance (Kirilina, 2013, p. 20) necessary to achieve strategic objectives of the University.

The principles that formed the system of personal performance evaluation for RSSU employees are following:

- Generality. All RSSU employees and managers are to be evaluated.

- Objectivity and complexity. The evaluation is performed directly by manager and is based on: employee's self-evaluation, objective personal performance data, constant employee's activity and conduct monitoring.

- Transparency. Every employee must know: personal performance evaluation principles, description of evaluation scale, efficiency level key requirements, current tasks, key indicators and evaluation criteria in current evaluation period.

- Feedback principle. Every manager should provide the opportunity to feedback for employees - to inform of evaluation results, give recommendations and advice concerning increase of productivity and efficiency.

- Opportunity to appeal. The evaluation results could be appealed successively: to the superior and anyone in up-going administrative hierarchy up to supervising vice-president, in labour disputes commission (possible at any stage of the appeal).

- Fair motivation and development principle. The results of evaluation are used: to determine additional payment and bonus rate, to determine the necessity of advanced professional training or reeducation of an employee, to make a decision to promote an employee. 
- Openness. The employees' evaluation results are available according to the system of seniority.

\subsection{Indicators and Criteria for Evaluating Staff}

An effectiveness of any employee evaluation technique particularly depends on accuracy of chosen indicators and criteria of evaluation (Kirilina \& Buzmakova, 2013, p. 180). And here a lot of questions arise. More likely, the reason why problems arise is that "показатель-pokazatel" (indicator) is a Russian word, and our (Russian) inspectors are not used to speak Russian. The word "pokazatel" in Russian comes from the word "to show" and means the characteristic of a process (an object, a phenomenon), which can be measured. The foreign word

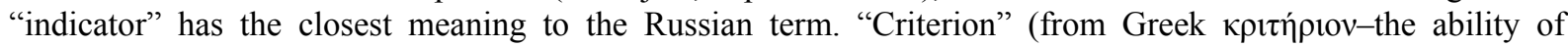
distinction, mechanism for estimation, a measure) means characteristic, fundamental, a rule for making a decision to estimate something as to the demanded claims (measure).

As indicators of personal performance evaluation for RSSU employees the following were defined:

- Personal productivity (Mikhalchenko \& Shevelev, 2012, p. 21).

- Improving of professional knowledge.

- Innovation (optimization) of work (education) process.

- Customer focus.

- $\quad$ Team work (Chulanova, 2008, p. 69).

It was decided to evaluate these indicators according to five-grade letter scale:

A-significantly exceeds expectations;

B-exceeds expectations;

C-meets expectations;

D-needs improvement;

E-does not meet expectations.

The description of evaluation criteria were composed in the following manner:

\subsubsection{A-Significantly Exceeds Expectations (An "Image" of a Perfect Employee)}

Personal productivity:

- The amount of accomplished planned and extra tasks significantly exceeds an average number for one employee of exact department, given the high quality of their accomplishment even during periods of extreme workload;

- $\quad$ Suggested and taken decisions are of creative manner and prospectivity (Makarova, 2011, p. 86);

- Shows initiative and readiness to have extra tasks (in absence of a colleague);

- Extremely independent: independently solves problems within his competence which hamper his personal efficiency and group efficiency (Kibanov et al., 2014);

- Has no episodes of labour discipline violation;

- An example of duty performance for other employees.

Improving professional knowledge:

- Constantly improves his professional knowledge;

- Studies best practices and modern methods of work within his field of practice;

- Willingly participates in professional seminars and workshops;

- Uses actively gained knowledge and experience to upgrade his colleagues' qualification.

Innovation (optimization) of the work (education) process:

- Proposes valuable innovative ideas for improving the quality of work and productivity of labor within the department and acts as a leader of the department implementing these ideas;

- Actively shares his innovative experience with colleges (the agent of innovations).

Teamwork:

- Effectively cooperates with all members of the group; 
- $\quad$ Places group interests higher than personal interests (only functional);

- Takes the initiative in search of mutual solutions;

- Acts as an example of communication culture in the group.

Focus on the customer:

- Has and uses the whole range of information about services which he can provide within his competence;

- The employee's methods of work are recommended by the management as reference for other employees of the department.

\subsubsection{B-Exceeds Expectations}

Personal productivity:

- Timely and accurately performs his office duties, even in periods of extreme workload;

- Shows a high level of labor productivity in the department and a significant level of quality;

- Tasks (processes) are accomplished completely and carefully on time or ahead of the schedule;

- Independent, proactive;

- Able to take on additional work during periods of heavy workload;

- No cases of labor discipline and labor regulations violation.

Improvement of professional knowledge:

- Improves his professional knowledge;

- $\quad$ Explores best practices and modern methods of work in his field, but not always uses them in practice;

- Participates in professional workshops and trainings with the desire and interest;

- Uses the acquired knowledge and experience to improve his own skills.

Innovations (optimization) of the work (education) process:

- Proposes innovative ideas to improve the quality of work and productivity within the department and tries to implement them in his professional activities;

- Willing to become an "agent of innovations".

Teamwork:

- Collaborates with all members of the group;

- Searches for mutual solutions;

- Strongly supports the culture of communication in the group.

Focus on the customer:

- Seeks to use the full range of information in his activity about the services possible to provide within competence;

- Understands the needs of customers and seeks the best way to meet these needs;

- Resolves conflict situations independently.

3.2.3 C-Meets the Expectations (An "Image" of a Good Employee)

Personal productivity:

- Accomplishes tasks and functionality provided by official duties in general;

- Shows a medium level of labor productivity and an acceptable level of quality in department;

- Tasks (objectives) are fully accomplished-amount of accomplished work corresponds to the average number per employee in exact department;

- Work (tasks) are accomplished on time from the first presentation, the formalization corresponds the requirements;

- Independent, does not require constant monitoring;

- Doesn't take on additional work during periods of low workload;

- No cases of labor discipline and labor regulations violation or prevented by the manager. 
Improvement of professional knowledge:

- Improves professional knowledge;

- Takes part in professional trainings and seminars;

- Uses the gained knowledge and experience performing his official duties.

Innovations (optimization) of the working (education) process:

- Takes part in the implementation of innovative ideas to increase quality of work and labor productivity within the department.

Team work:

- Cooperates with a team of colleagues without isolation within his own duties, seeks for mutual solutions;

- Able to support his colleague in to reach team result.

Focus on the customer:

- Effectively and friendly communicates with consumers (customers);

- Understands the consumer's (customer's) needs;

- Independently solves conflict situations.

3.2.4 D-Needs an Improvement:

Personal productivity:

- Doesn't complete the amount of given tasks and functions in a full scope;

- Quality of work and labor productivity are lower than other department employees';

- Tasks are not fully accomplished - amount of accomplished tasks is lower than an average amount of tasks for a single employee in the exact department;

- Accomplished tasks are insufficiently detailed, requiring a partial completion by a performer or by the management of the department;

- Tasks are accomplished with a violation of established timeframe;

- Rejects to take an additional workload even in case of utter production necessity;

- Requires to be controlled during the work process.

Improvement of professional knowledge:

- Improves a professional knowledge insufficiently;

- Takes part in professional trainings and workshop unwillingly;

- Not aspired to use the gained knowledge and experience performing their own duties.

Innovations (optimization) of the working (education) process:

- Not always involved in implementation of innovative ideas to improve work quality and labor productivity within the department;

- Challenges the positive innovative experience of colleagues;

- Constantly shows skepticism.

Team work:

- Cooperates with colleagues insufficiently, joint discussions often lead to conflicts;

- Insists on his point of view at the expense of group interests;

- Commentaries on culture of communication exist.

Focus on the customer:

- Insufficiently friendly;

- Personal interests and working rules are above the customer's ("come back tomorrow"). 


\subsubsection{E-Doesn't Meet Expectations (An “Image” of the Bad Employee)}

Personal productivity:

- Doesn't cope with the scope of the assigned tasks and functions;

- Quality of work and labor productivity is much lower, than other workers' of the department;

- Tasks (works) are accomplished not complete, or not accomplished at all;

- Tasks (works) are accomplished insufficiently careful, require processing by the performer, the attention of the manager is always necessary;

- Tasks (works) are constantly accomplished with violations of established timeframe;

- Refuses to take any additional amount of work under any conditions;

- Needs a constant control during work.

Improvement of professional knowledge:

- Is not engaged in improvement of professional knowledge;

- Reluctant to participate in professional workshops and trainings;

- Knowledge and experience are not used in the implementation of duties.

Innovations (optimization) of the working (education) process:

- Not involved in implementation of innovative ideas to improve work quality and labor productivity within the department;

- Challenges the positive innovative experience of colleagues;

- Constantly shows skepticism.

Team work

- Cooperates with colleagues insufficiently, joint discussions usually lead to conflicts;

- Insists on his point of view to at the expense of group interests;

- Commentaries on culture of communication exist.

Focus on the consumer:

- Insufficiently friendly;

- Personal interests and working rules are above the customer's (“come back tomorrow");

- Reasonable customer's claims to the work of the employee are recorded.

\section{Discussion and Approval Procedures}

Procedure and order of personal efficiency assessment for RSSU employees were defined by the following provisions:

- The direct manager sets tasks for employees for appraisal period;

- During the quarter the direct manager watches the activities and behavior of employees;

- Workers carry out a self-assessment and forward it to the direct manager not later than the $20^{\text {th }}$ date after the end of the quarter;

- Not later than the $27^{\text {th }}$ date the direct manager receives a self-assessment of employees and puts down marks according to five indicators and a total quarter assessment;

- Till the $28^{\text {th }}$ date total assessments are coordinated and approved by higher management;

- Till the $28^{\text {th }}$ date an assessment and individual bonus coefficients are entered to the automated accounting and bonus distribution system;

- Till the $31^{\text {st }}$ date there bonus payment happens;

- Not later than the $10^{\text {th }}$ date of the second month following reporting quarter, assessments are reported to workers. The direct manager discusses with the worker via feedback his results and expectations for the next assessment period (not less than once a year);

- In the end of the assessment cycle: in case of a disagreement with the manager's assessment, the employee can appeal to the higher management and to the commission on labor disputes. 


\subsection{Making Total Assessments to Employees}

The head of the structural unit was recommended to provide feedback with the employee during the whole quarter. The worker was recommended to address personally and periodically the direct manager for the feedback. The direct manager has to give feedback according to the results of an assessment to workers, paying special attention to those workers whose self-assessment differs from the manager's assessment.

Assessing the personal efficiency of RSSU employees, assessment have to be made in terms of each indicator according to compliance of work results to description of criteria in exact quarter (Belkov, 2012). The total assessment is made as a sum of administrative assessments of the direct manager. Making total assessments to employees, the manager is obliged to follow the listed rules, shown in Table 1:

Table 1. The rules for determining assessments

\begin{tabular}{ll}
\hline Total quarter assessment & Estimates according to indicators \\
\hline To put 'A' & The majority of estimates has to be 'A', no 'E' and 'D', no more than one 'C' \\
Can't be 'E' & If there at least one 'A' \\
Can't be 'A' & If there at least one ' $E$ ' \\
\hline
\end{tabular}

The total assessment is made as a sum of overall quarter estimates. Herein, if one quarter assessment of a worker is 'A' or ' $\mathrm{E}$, so the annual assessment can't have extreme opposite value of ' $\mathrm{E}$ ' or ' $\mathrm{A}$ '. If estimates of three of four quarters have identical value, the annual assessment has to have of the same value.

The 'A' assessment includes only the level of personal efficiency. Employees regularly receiving ' $A$ ' rate are considered to be prime candidates to get higher vacant higher positions. The behavior, productivity and personal qualities of the employee receiving ' $A$ ' rate can be a reference for colleagues. The quantity of 'A' rates in one department, as follows from table 2, is limited:

Table 2. Maximum number of ' $A$ ' rates on the basis number of employees in one department

\begin{tabular}{ll}
\hline Number of employees in one department & Maximum number of 'A' rates \\
\hline More than 30 & $10 \%$ of total amount of assessments \\
$21-30$ & 3 assessments \\
$10-20$ & 2 assessments \\
Less than 10 & 1 assessment \\
\hline
\end{tabular}

\subsection{Calculation of an Employee's Award}

Proceeding from the received assessment, calculation of the individual size of an award of the worker in system of an assessment of personal efficiency of workers of RSSU has to be carried out. The structure of employee's remuneration allows defining what elements form the employee's remuneration. In general the employee's remuneration has the following view:

$$
\mathrm{ERL}=\mathrm{BW}+\mathrm{EW}+\mathrm{RER}+\text { Bonus }+\mathrm{FA}
$$

Where:

ERL-Employee's Remuneration of Labour;

BW-Basic Wage;

EW-Extra Wage;

RER-Remuneration for the End Result;

Bonus-Bonus for the main results;

FA-Financial Aid.

Basic wage ( $B W$ )-provides the minimum wage on condition of working off the necessary quantity of working 
hours, stimulates the development of skills and professional development of the worker.

Extra Wage ( $E W$ )-includes different types of surcharges, extra charges and compensations for differentiated working conditions and qualification of the worker. It includes:

- Bonuses for combining of posts and additional duties;

- $\quad$ Surcharge for work over 40 hours per week;

- Class rates bonuses for drivers;

- Personal bonuses for managers and professionals for qualification;

- Payments for overtime of work during day offs and holidays;

- Other individual payments.

Remuneration for the end result (RER)-it is paid from compensation fund for achievements in certain activity of the University, separate structural divisions. The remuneration stimulates group interests, encourages corporate spirit in achieving of the end results and it is distributed according to Individual Performance Factor. Remunerations are paid for the following results:

- Labor productivity growth;

- Improvement of quality of work (services);

- Implementation of inventions and improvement suggestions;

- Economy of resources (material, technical, financial, power, etc.);

- Other types of the reached results;

- Payment of remunerations is funded from additional salary budget.

Financial aid is paid from material incentives fund out of profit and is aimed to provide social guarantees and the benefits for employees of RSSU. Material aid is paid in case of emergency in the form of compensation payments in emergency or extreme situations:

- Death of the employee or his close relatives;

- Wedding of the employee;

- For acquisition of drugs or paid treatment of the employee;

- In case of an accident (fire, trauma, property loss etc).

Financial support is provided according to the personal application of the employee on the basis of RSSU president's order and can b qualified as an episodical form of remuneration.

Bonus for the main results-stimulates to meet end results.

An actual amount of quarter bonus depends directly on a personal efficiency of the employee. The calculation of the employee's individual amount of bonus is performed by setting an exact individual bonus coefficient $\mathrm{K}_{\text {ind }}$ according to the quarter and annual results. It is calculated by formula:

$$
\mathrm{K}_{\text {ind }}=\mathrm{K}_{\text {norm }} * \mathrm{~K}_{\mathrm{KPI}} * \mathrm{~K}_{\mathrm{bon}} * \mathrm{~K}_{\text {serv }}
$$

Where:

$\mathrm{K}_{\text {norm }}$-norm coefficient of bonuses (Table 3);

$\mathrm{K}_{\mathrm{KPI}}-$ coefficient of dependence from department $\mathrm{KPI}$;

$\mathrm{K}_{\text {bon }}$-bonus coefficient (Table 4);

$\mathrm{K}_{\text {serv }}-\mathrm{RSSU}$ record of service coefficient (Table 5). 
Table 3. Standard bonus coefficients (from an official salary)

\begin{tabular}{lcc}
\hline \multirow{2}{*}{ Grades of employees } & \multicolumn{2}{c}{ Standard bonus coefficients } \\
\cline { 2 - 3 } & Quarter & Year \\
\hline $01-07$ & 0,5 & 1,0 \\
$08-12$ & 1,0 & 2,5 \\
$13-17$ & 1,0 & 4,0 \\
$18-27$ & 1,5 & 6,0 \\
\hline
\end{tabular}

Coefficient of dependence from department KPI: $0.1 \geq K_{\mathrm{KPI}} \geq 1$

Table 4. Bonus coefficient

\begin{tabular}{lc}
\hline Resulting Assessment & Range of bonus coefficient $\mathrm{K}_{\text {bon }}$ \\
\hline A & $1.60-2.00$ \\
B & $1.11-1.59$ \\
C & $1.00-1.10$ \\
D & $0.60-0.99$ \\
E & $0.01-0.59$ \\
\hline
\end{tabular}

Table 5. RSSU record of service coefficient

\begin{tabular}{ll}
\hline RSSU record of service & Coefficient $\mathrm{K}_{\text {serv }}$ \\
\hline from 1 year to 3 years & 1.1 \\
from 3 to 5 years & 1.2 \\
from 5 to 7 years & 1.3 \\
from 7 to 10 years & 1.5 \\
From 10 to 15 & 1.7 \\
from 15 to 20 years & 1.9 \\
More than 20 years & 2.0 \\
\hline
\end{tabular}

Results of the RSSU employees' personal efficiency assessment are kept in RSSU Personnel Administration and in structural divisions. Besides that, the results of the RSSU employees' personal efficiency assessment are surely represented at any staff appointments.

\section{Conclusion}

Summing up the result, it can be stated that the developed RSSU employees' personal efficiency assessment became an important element of forming high-skill, high-performance the RSSU team, sharing the values of corporate culture of the university. Its main direction of development in the XXI century-the formation of the man of the future (Vinichenko, 2014, p. 21). In general the system of human capital and talents management formed the following view:

A. Subsystem of talents engagement and human capital development:

- System of starting grants, competitions of initiative projects, foreign trainings, allowing achieve quickly a qualitative leap in productivity of each worker;

- Accurately built career ladder-the sequence of the job positions changing each other, according to the organizational structure and defining a direction of the employee, dividing the directions according to activity profiles;

- Individual programs of development and professional development of employees, the development of mentoring and leadership institution, either for ensuring the steady of career growth, or for strengthening the scientific schools of RSSU; 
- Strong Labor union of RSSU employees-the system of social protection for each member of RSSU team including the "health" program providing improvement of employees' health.

B. Subsystem of labour remuneration:

- The integrated naming of all posts, regardless to structural division;

- Forming of a clear remunerations limits for all posts and in all divisions of RSSU;

- Simple, clear, transparent, fair rules of calculation and salaries payroll, hiring, rotation, dismissal.

C. Labour efficiency management system (Kryukova \& Sokolova, 2014):

- $\quad$ Each team member involvement;

- Satisfaction of team with working conditions and quality of training;

- Assessment of team productivity using the advanced methods of assessment.

Analyzing the experience of other organizations to introduce a similar system of evaluation, it should be noted that to date it is not yet widely used. However, the tendency of expansion of this experience is activated. On the eve of 2015 the authors have negotiated a similar project in corporation "Udarnitsa", the factory management was interested in the development of technology assessment namely administrative and management personnel. Part of this technology has been successfully applied in Togliatti State University, a number of secondary schools in Moscow. As for technology, "Five+" Sberbank of Russia, which was the basis of the presented system, it can be stated that its effectiveness verified by experience. According to the bank's management, experts and employees themselves, this system significantly stimulated the activity of sales of banking products, improve service and employee productivity, and stimulate their career.

It needs to be noted that the objective to implement the effective technologies of employee's personal efficiency assessment is currently one of the major tasks for domestic higher education institutions. Therefore practical application of the developed technique, as it appears to be, will provide an essential increase of the university efficiency.

\section{References}

Ageev, N. V. (2010). The use of expert-intuitive methods in predicting management systems. Social Policy and Sociology: An interdisciplinary scientific journal, 5, 14-24.

Alekseev, Y. V., Patrushev, V. I., \& Semenets, N. V. (2013). The new ideology and philosophy of sustainable development of the noosphere (the modern concept of human capital, management of its development and evaluation of social and environmental risks). Human capital, 7, 15-19.

Baklanov, P. A. (2006). Methodical recommendations on defining of efficiency and productivity indicators for professional office activity of civil servants in the Federation Council within the competence of the upper house of Federal Assembly of Russia. Moscow, M: Federal Assembly of the Russian Federation.

Baklanov, P. A. (2012). Instrumental-symbolic models in organizational and human activities (Textbook). Moscow, M: Ed. House MISaS.

Belkov, B. B. (2012). Experiment of Russian companies on development and use of professional standards and competence models in comparison wit. Human resources and intellectual resources management in Russia, 3, 24-28. http://dx.doi.org/10.12737/120

Bondaletov, V. V. (2007). Social and protest activity of the military personnel. Sociological researches, 11, 93-100.

Chulanova, O. L. (2008). Technologies for effective teambuilding in personnel management. Science, economics, law in the regions of Russia: Materials of the All-Russian scientific and practical conference (Nizhnevartovsk, April 24 2008). Russian, Nizhnevartovsk: NGGU.

Chulanova, O. L. (2014). Personnel management based on competencies. Moscow, M: INFRA-M. http://dx.doi.org/10.12737/3433.

Fionova, L. R. (2014). Assessment of the government employees' readiness to work in the e-government. Theory and practice of social development, 1, 73-77.

Kaurova, O. V., Kryukova, E. M., Maloletko, A. N., Deryabina, A. V., \& Yumanova, O. S. (2014). Modern trends in development of tourism statistics in the world and in Russia. Life Science Journal, 11(4), 451-454.

Kibanov A. Y., Mitrofanova, E. A., Konovalova, V. G., \& Chulanova, O. L. (2014). The concept of 
competence-based approach to human resource management: Monograph. Moscow, M.: SIC INFRA-M. http://dx.doi.org/10.12737/852.

Kibanov, A. Ia. (2013). Building a motivational core of the organization's personnel. Theory and practice of management of the organization as a social and economic system: The identification, analysis and resolution of problems formation. Proceedings of the September 2013 International Conference (pp. 71-81). Finland, Helsinki.

Kibanov, A. Ia. (2014). Human resource management bases (3nd ed.). Moscow, M: INFRA-M. http://dx.doi.org/10.12737/4118.

Kirilina, T. Yu. (2013). Sociology of morals in Russia: Past, Present and future. Sociological researches, 6, 17-24.

Kirilina, T. Yu., \& Buzmakova, T. I. (2013). Spirituality and morality of the russian youth in the sociological dimension. Social policy and sociology, 3, 169-183.

Kirillov, A. (2014). Compliance with the principles of management in HR outsourcing. Kadrovik, 9, $102-109$.

Kryukova, E. M., \& Sokolova, A. P. (2014). Assessment of Efficiency of the Hotel Management by a Russian Company. World Applied Sciences Journal, 30, 51-54. http://dx.doi.org/10.5829/idosi.wasj.2014.30.mett.25

Makarova, L. V. (2011). Innovative model of personality in the context of the ethics of personalism. Innovations, $1,85-89$.

Mikhalchenko, E. V., \& Shevelev, G. E. (2012). Improvement of the corporate culture of a commercial bank through motivation. The Tomsk Polytechnic University, T. 320, 6, 18-22.

Urzha, O. A., Argunova, L. G., Frolova, E. V. et al. (2009). Scientific and methodical supply to HR potential in high education. Moscow, M: RSSU.

Vinichenko, M. V. (2014). Innovative development of personality in the course of training for managerial specialties. Human resources and intellectual resources management in Russia, 4, 21-25. http://dx.doi.org/10.12737/5418

Voltchkova, L. T., \& Rasskazov, C. V. (2009). "Popular" investments into social production: A social and administrative analysis. Sociological researches, 2, 16-28.

\section{Copyrights}

Copyright for this article is retained by the author(s), with first publication rights granted to the journal.

This is an open-access article distributed under the terms and conditions of the Creative Commons Attribution license (http://creativecommons.org/licenses/by/3.0/). 